\section{LA TRANSICIÓN DEL BRONCE FINAL AL HIERRO I EN EL SUR DE LA MESETA NORTE. NUEVOS DATOS PARA SU SISTEMATIZACIÓN}

\author{
THE TRANSITION FROM LATE BRONZE \\ AGE TO IRON AGE I IN THE SOUTH \\ OF THE NORTHERN MESETA. \\ NEW FACTS FOR ITS SYSTEMATIZATION
}

\section{J. FRANCISCO FABIÁN GARCÍA (*)}

\section{RESUMEN}

La transición entre el Bronce Final y la I Edad del Hierro en el Sur de la Meseta Norte ha conocido una cierta polémica. Según la lectura del registro arqueológico disponible, basado fundamentalmente en la estratigrafía de Los Castillejos (Sanchorreja, Ávila), F.J. González-Tablas ha venido manteniendo durante algo más de una década la tesis de la perduración en el Sur de la Meseta Norte de Cogotas I, más allá de la cronología final que se le daba para el centro del valle del Duero, considerando que esta zona de la Meseta había tenido su particular Hierro I al margen del Valle del Duero. Nuevos datos indican ahora que en el Sur de la Meseta Norte la evolución cultural a partir del Bronce Final fue en todo similar a la de la cuenca del Duero Medio, siendo la cultura del Soto de Medinilla, como allí, la fase intermedia hasta la Segunda Edad del Hierro.

\begin{abstract}
The transition between Late Bronze Age and Early Iron Age in the south of the Northern Meseta (Spain) has been the subject of controversy. The interpretation of the available archaeological record proposed by F.J. González-Tablas, based on the stratigraphy from Los Castillejos (Sanchorreja, Avila), has maintained the idea of the survival of Cogotas 1 in the South of the Nort Meseta later than in the centre of the Duero valley. New data now indicate that in

(*) Unidad Técnica de Arqueología, Servicio Territorial de Educación y Cultura. Plaza Fuente del Sol, 1. 05001 Ávila.

El artículo fue remitido en su versión final el 4-X-99.
\end{abstract}

the southern part of the northern Meseta cultural development from the Late Bronze Age onwards was in every way similar to that in the Duero basin: the Soto Culture, as in the Duero, being an intermediate stage until the Second Iron Age.

Palabras clave: Cogotas I. Hierro I. Meseta:

Key words: Cogotas I. Hierro I. Meseta.

\section{INTRODUCCIÓN}

La transición del Bronce Final a la Edad del Hierro y la primera fase de éste, el Hierro I en el Sur de la Meseta Norte, ha dado lugar a una polémica científica continua en las últimas décadas que no ha logrado todavía un consenso entre los investigadores. El hecho de que la cuestión principal, el eje de las discrepancias, afecte aspectos de base tales como la propia seriación de etapas y/o fases y su correspondiente filiación, supone una cuestión de suma importancia para entender la secuencia cultural de ese momento en el Sur de la Meseta Norte y avanzar con seguridad hacia otros aspectos. Mientras que en zonas próximas como el centro del valle del Duero, trabajos antiguos y recientes han permitido clarificar este aspecto desde hace tiempo, aquí la polémica y las dudas han llegado hasta el presente, propiciadas por la carencia de trabajos arqueológicos de prospección y de excavación sistemática de cierta entidad. 


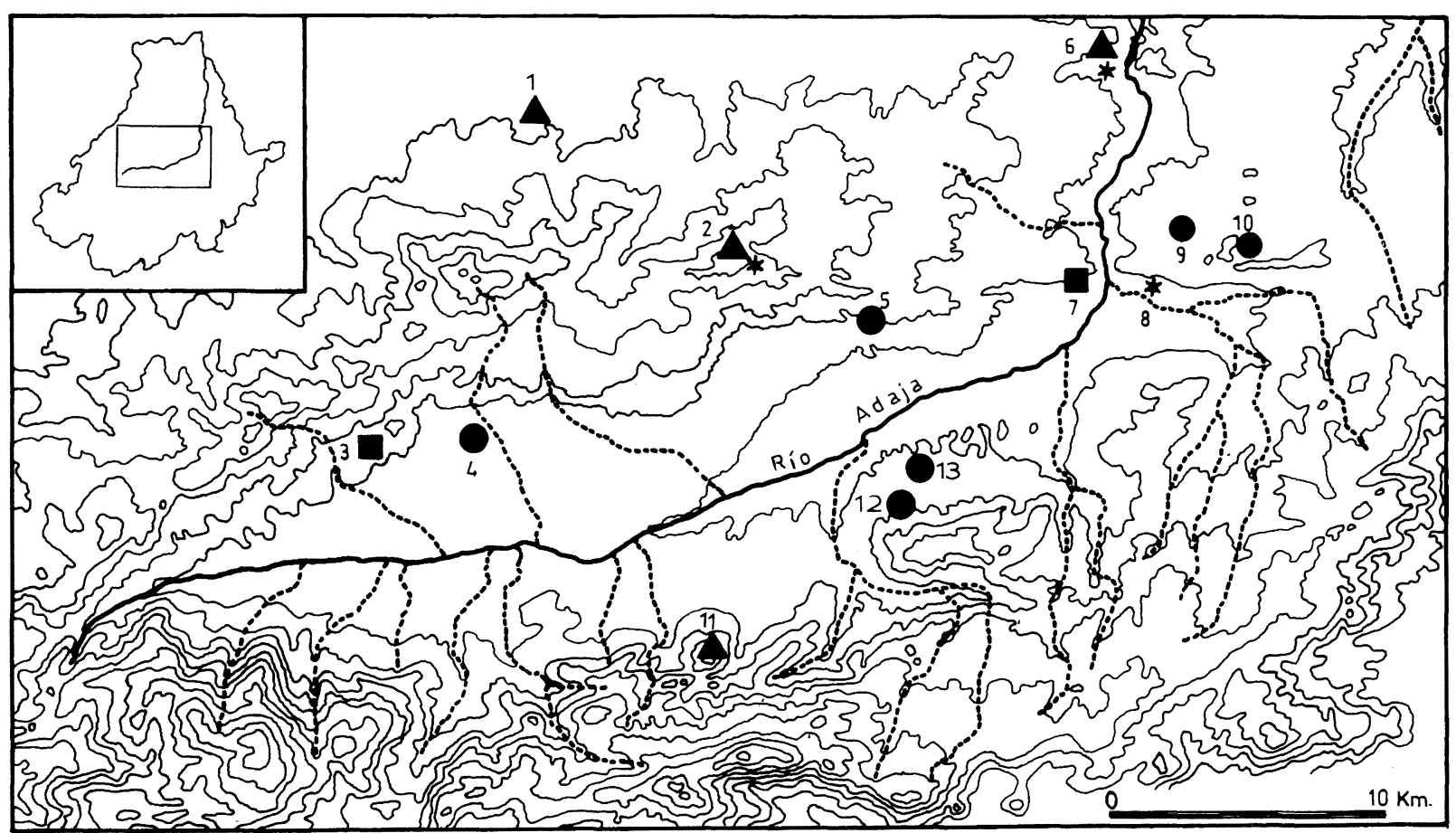

Fig. 1. Yacimientos correspondientes al Bronce Final y a la Edad del Hierro en el Valle Amblés (Ávila).

* Cogotas I. - Soto Inicial. Cogotas I + Soto Inicial. $\Delta$ Hierro II.

1 La Mesa de Miranda (Chamartín). 2 La Lomilla (Muñopepe). 3 Las Zorreras (Muñana). 4 Los Arenalones (Guareña). 5 Los Castillejos (Sanchorreja). 6 Las Cogotas (Cardeñosa). 7 Cerro de la Cabeza (Ávila). 8 La Viña Vieja (Ávila). 9 Guaya (Berrocalejo de Aragona). 10 La Solana Angosta (Bernuy-Salinero). 11 Ulaca (Solosancho-Villaviciosa). 12 El Campillo (Gemuño). 13 El Pradillo (Gemuño).

Este trabajo pretende, en primer lugar, aportar datos empíricos novedosos, completando con ello una geografía carente en gran medida de yacimientos fechables en la transición del Bronce Final al Hierro I y del Hierro I propiamente (Fig. 1). Una parte de estos datos proceden de las diversas campañas del reciente Inventario Arqueológico de Ávila y otra de hallazgos casuales y búsquedas selectivas de yacimientos a partir de un patrón previamente conocido. En segundo lugar, trata de clarificar la secuencia cultural entre el Bronce Final y el Hierro II de la zona de que se trata, revisando las posturas mantenidas hasta el momento a la vista del nuevo registro. Desde luego no busca ser todavía un proyecto de estudio espacial para las etapas referidas, como el publicado para el centro delValle del Duero (Quintana y Cruz, 1996). Es, solamente, una contribución al establecimiento de una base más clara desde la que emprender nuevos proyectos de investigación. La reciente publicación de J. Quintana y P.J. Cruz (1996) conjuntando e interpretando todos los datos conocidos y publicados para el centro del valle del Duero, es referencia obligada para este trabajo por proximidad geográfica, por tratarse de un estudio basado en un mayor número de datos y por la similitud evidente entre los procesos culturales y los registros arqueológicos de ambas zonas.

\section{LA BASE DOCUMENTAL DISPONIBLE ACTUALMENTE}

Los yacimientos excavados que han intervenido en la problemática hasta donde está planteada en este momento serían: Cancho Enamorado, dentro del complejo conocido como Cerro del Berrueco, entre las provincias de Ávila y Salamanca; Las Cogotas (Cardeñosa) y Los Castillejos (Sanchorreja), ambos en Ávila, y en Salamanca, La Plaza de San Martín (Ledesma), El Cerro de San Pelayo (Martinamor) y El Cerro de San Vicente (Salamanca) (Fig. 1). Todos ellos son conocidos ya a través de la bibliografía. Además, habría que añadir las excavaciones de urgencia llevadas a cabo en la pro- 
vincia de Ávila, en El Cerro de la Cabeza (Ávila) y Las Zorreras (Muñana), ambos en la unidad geográfica conocida como Valle Amblés (Fig. 2). En el primero, el resultado de la excavación está en fase de estudio y en el segundo no ha sido publicado como tal nada, aunque se dispone de la memoria de los trabajos (1).

En el imponente poblado de Cancho Enamorado, en lo alto del Cerro del Berrueco, Maluquer de Motes llevó a cabo excavaciones en los años cincuenta, resultando corresponder, para nuestros conocimientos actuales, al Bronce Final, a la cultura de Cogotas I. Los resultados de aquellas excavaciones no tendrían propiamente lugar en este trabajo a no ser por el problemático hallazgo de un lote de hierros (una navaja de afeitar, una hoja de cuchillo, dos escoplos, un punzón y una anilla amorfa) en el nivel inferior de la choza individualizada como $B e$ 2. En ella Maluquer de Motes distinguió dos niveles de habitación similares atendiendo a la tipología de las cerámicas y separados entre sí por otro estéril. Fue en el inferior, en contacto con la roca madre, en el que Maluquer de Motes (1958: 46-48) halló dicho lote. En la misma publicación aludía a otros hallazgos de hierro y de bronce atribuidos supuestamente al mismo yacimiento, aunque procedentes de las múltiples colecciones privadas que han surgido a partir de la extraordinaria abundancia de materiales que los yacimientos del Bronce Final y de la Edad del Hierro han deparado, propiciando de paso, un lamentable expolio. Sólo sería fiable en principio el lote de hierros de la choza $\mathrm{Be} 2$. Las fíbulas de doble resorte sencillas o de puente cruciforme y las de codo y pie largo que Maluquer de Motes incluyó en Cancho Enamorado a partir de las noticias que tuvo, en realidad, pudieron haber aparecido en la superficie de ese poblado o no, correspondiendo en este caso a cualquiera de los dos poblados clasificables al menos en la II Edad del Hierro, situados en la base del Cerro del Berrueco. En muchos casos la denominación genérica Cerro del Berrueco, arrastrada hasta el presente desde la bibliografía antigua, ha provocado una cierta confusión al localizar con esa referencia materiales cuya procedencia exacta dentro del complejo arqueológico del Berrueco se desconocía, restando por tanto posibilidades de mejor interpretación.

(1) J. Caballero, L.C. García-Cruces y F. Porres, "Informe de la excavación arqueológica de urgencia en el yacimiento de Las Zorreras, término de Muñana, Ávila", 1991. Trabajo manuscrito inédito depositado en la Unidad Técnica de Arqueología del Servicio Territorial de Educación y Cultura de Ávila.
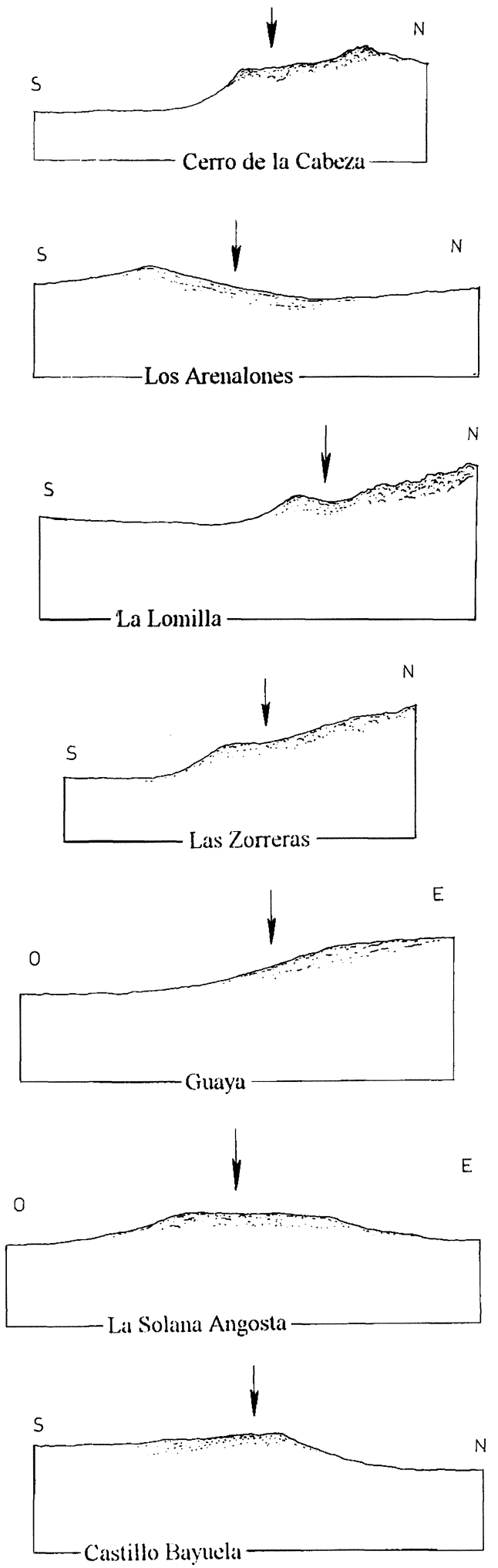

Fig. 2. Perfiles topográficos correspondientes a los yacimientos del Hierro I en la provincia de Ávila. 
Desde los trabajos de Maluquer de Motes no se han realizado otros en Cancho Enamorado salvo los de prospección y recopilación de hallazgos casuales, por tanto sus datos, debidamente revisados en la actualidad, son toda la información que poseemos sobre este yacimiento. Cancho Enamorado contiene en su estratigrafía un sólo momento cultural, correspondiente a la cultura de Cogotas I. La tipología de sus cerámicas y sus decoraciones hacen pensar que se trata de un momento medio y final dentro de esa cultura, sin conexión con la etapa siguiente. La continuidad podría estar en alguno de los poblados de la Edad del Hierro situados en la base misma del cerro donde se encuentra Cancho Enamorado: Las Paredejas y Los Tejares, ambos de gran importancia, sólo estudiados a partir de conjuntos de piezas recogidas por los labradores al cultivar las tierras (Piñel, 1976; Fabián, 1985, 19867). Por algunos de estos hallazgos podría pensarse, al menos para el de Las Paredejas, que es la fase siguiente a Cancho Enamorado, aunque sólo las excavaciones podrán confirmarlo con seguridad.

De momento el conocimiento que tenemos implicaría a toda o a buena parte de la Edad del Hierro, aunque por la trayectoria cronológica que se atribuye a algunas de las piezas, sobre todo las fíbulas, no es posible saber si son más o menos antiguas, al carecer de un contexto estratigráfico claro. No sería en absoluto descabellado considerar que el lote de hierros de la choza Be 2 de Maluquer de Motes proceda de algún escondrijo practicado por los habitantes de los poblados sucesivos, para los que sin duda las características físicas del monumental Cerro del Berrueco, con el poblado de Cancho Enamorado en su cima, tuvo que ser una referencia como mínimo defensiva en caso de necesidad.

En Los Castillejos de Sanchorreja (Ávila), Navascués y Camps realizaron entre 1931 y 1934 las excavaciones que Maluquer de Motes publicaría en 1958. En los años ochenta González-Tablas llevó cabo nuevos trabajos en el yacimiento, dando lugar a una novedosa interpretación general de los inicios de la Edad del Hierro en la zona, provocando de paso una importante polémica. Las investigaciones de una y otra época constataron dos momentos culturales y sucesivos que han venido denominándose Sanchorreja Inferior y Sanchorreja Superior o nivel Inferior y Superior. El primero corresponde a Cogotas I y el otro a la Edad del Hierro. En esto coincidieron los dos equipos de trabajo, aunque en lo que se refiere a la posición de algunos materiales en la secuencia del yacimiento difirieron considerablemente. Así Maluquer de Motes sitúa las cerámicas bícromas y las fíbulas de doble resorte, en el nivel inferior. González-Tablas (1990: 64), en cambio, a partir de sus excavaciones situará tanto a unas como a otras en el nivel superior. Llama la atención el hecho de que en el yacimiento no se haya encontrado un hiatus entre una fase y otra. Ello, sin duda, ha sido un elemento más para condicionar las teorías de González-Tablas.

Entre 1989 y 1990 se llevó a cabo una excavación de urgencia en la Plaza de San Martín, en Ledesma (Salamanca), municipio ubicado sobre un cerro granítico en un meandro del río Tormes, con buena posición defensiva, al igual que los aludidos de Cancho Enamorado y Los Castillejos y, como luego veremos, también, del de Las Cogotas. La estratigrafía que deparó se iniciaba con un nivel muy erosionado, apoyado en la roca madre, con materiales de Cogotas I, que los excavadores (Benet et alii, 1991: 119) equiparan cronológicamente con lo conocido para el Cerro de San Pelayo, en Martinamor (Salamanca) y el nivel V de la excavación de González-Tablas en Sanchorreja (nivel inferior), es decir paralelo a las últimas perduraciones de Cogotas I en los rebordes meridionales de la Meseta... en torno a la segunda mitad del siglo VIII a.C. Sobre él había lo que denominan un nivel de contacto con escaso material cerámico inequívoco de Cogotas I, cerámica pintada y algún hierro, cuya poca claridad cultural atribuyen a una acción antigua de terraplenado, cuyo resultado fue la alteración y mezcla de determinados componentes culturales e incluso la adición de alguno procedente de otro nivel. Es importante retener el dato de la existencia de un nivel de interposición, sucesor de la fase de Cogotas I e inmediato a la fase siguiente. Posteriormente y rompiendo claramente con lo anterior, se superponían niveles y construcciones culturalmente semejantes con cuatro fases sucesivas de cabañas circulares de adobe. La cerámica varía muy poco a lo largo de la secuencia, dándose recipientes de paredes finas muy cuidados, vasos carenados o globulares con cuello ligeramente vuelto, bases planas y pies realzados y decoraciones a base de incisiones, digitaciones y ungulaciones aplicadas en el labio. Las cerámicas pintadas son muy representativas con motivos en amarillo sobre fondo rojo y también en color blanco y azul. Hay, finalmente, algunos fragmentos de hierro asociados. Termina la secuencia con un nivel revuelto en el que se mezclan cerámicas de Cogotas II con cerámica de tipo celti- 
bérico y T.S.H. Los autores sospechan que pudiera haber habido un lapso de tiempo entre la primera ocupación y la de la Edad del Hierro, aunque estratigráficamente no quede constatada con la claridad deseable (Benet et alii, 1991).

En los años veinte J. Cabré excavó en el Castro de Las Cogotas reconociendo un nivel correspondiente a la Segunda Edad del Hierro, dentro del cual aparecían materiales intrusos correspondientes a la cultura de Cogotas I evidenciando una ocupación anterior. Explícitamente Cabré (1930: 45) dice que, salvo en algunas viviendas, en el poblado hay un sólo nivel arqueológico, apareciendo la cerámica más moderna y la más antigua juntas. Tal vez la mezcla puede deberse a la alteración del más antiguo durante la segunda ocupación o, en último caso, a la técnica de excavación utilizada en algunas cabañas. En los años ochenta, se han llevado a cabo nuevas excavaciones en Las Cogotas, en la zona que Cabré consideraba destinada a encerradero de ganados, sin que se haya observado una secuencia cultural continuada entre los dos momentos, ni la presencia de un nivel correspondiente a Cogotas I en el segundo recinto del yacimiento (Ruiz Zapatero y Álvarez Sanchís, 1995, 1998).

En el Cerro de San Pelayo, en Martinamor (Salamanca), a unos $18 \mathrm{~km}$ al Sur de la ciudad de Salamanca, las excavaciones de N. Benet (1990) a mediados de los ochenta dieron a conocer un horizonte, que era desconocido hasta ese momento en la zona. Se trata de un cerro bien destacado, coronado por un afloramiento rocoso, con muy buena posición estratégica dominando una importante extensión de la vega del río Tormes. Lo reducido de la excavación arqueológica sólo permitió la documentación parcial de una estructura en el nivelVI en la que aparecía un hogar, al lado del cual había tres recipientes cerámicos, dos lisos y uno decorado con vistosos motivos geométricos pintados en el interior que, a juicio del excavador, estarían emparentados con algunos recipientes hallados en la ría de Huelva y que, a su vez, tienen relación con las cerámicas de retícula bruñida (Benet et alii, 1991: 134). Las fechas de C-14 para el nivel VI, aunque en otro punto distinto de donde aparecieron los recipientes, fueron: $765 \pm 30$ y $710 \pm 30$ a.C. En las referencias bibliográficas a este yacimiento no se cita cerámica correspondiente a Cogotas I pero sí, en cambio, a la etapa campaniforme, con lo cual puede entenderse que la ocupación del Hierro I en el Cerro de San Pelayo es una rehabitación del yacimiento dentro de su historia particular.
En las proximidades de la ciudad de Ávila se ha llevado a cabo recientemente una excavación de urgencia de una cierta magnitud, cuyos resultados se hallan aún en la fase de estudio preliminar (2). Se trata de El Cerro de la Cabeza (Figs. 1-3), un extenso yacimiento con ocupación desde el Calcolítico hasta, al menos, el Hierro I. Pero tan densa ocupación no ha producido en lo excavado una situación de estratigrafía vertical, sino horizontal es decir su secuencia es reconstruible a partir del estudio individualizado de los materiales con una adscripción cultural clara y de algunos conjuntos cerrados (fosas o restos de cabañas). Una de las hipótesis para interpretar el uso dilatado del sitio es la explotación de la malaquita, que de forma frecuente y concentrada aparece allí mismo, visible todavía en la actualidad. La infrecuencia de hallar en territorio abulense tantas ocupaciones sobre un mismo espacio, sin características distintas a las de otros muchos inmediatos, la presencia de malaquita y la constatación de hallazgos de crisoles abandonados, incluso al pie de hogares, hace pensar que se tratara de ocupaciones relacionadas con la explotación de cobre. Para lo que aquí fundamentalmente interesa, hay que decir que han aparecido abundantes testimonios de una ocupación correspondiente al Bronce Final, posiblemente a una etapa muy final dentro de este periodo y que los que implican al Hierro I están compuestos por numerosas cerámicas, tanto de la etapa más inicial del Horizonte del Soto de Medinilla, como de una fase más avanzada dentro de éste, sin llegar, al parecer, a la fase II. Por tanto podría sospecharse la continuidad en la habitación del yacimiento entre Cogotas I y el Hierro I.

El otro yacimiento abulense donde se han llevado a cabo excavaciones es Las Zorreras (Figs. 1-2, 4), en el municipio de Muñana, a $24 \mathrm{~km}$ al Oeste del anterior, igualmente también en el Valle Amblés y, como en el caso del Cerro de la Cabeza, en una situación similar al borde del fondo del valle. A principios de los noventa se llevó a cabo una excavación de urgencia, dirigida por C. García-Cruces para conocer el estado del yacimiento, después de que el acondicionamiento para una plantación de pinos no controlada produjera gravísimos daños. El resultado de estas excavaciones y las prospecciones superficiales en las tierras alteradas han permitido, por una parte, documentar que la estratigrafía en la zona afectada por la plantación está completamente al-

(2) Las excavaciones han sido dirigidas por Fco. Javier Sanz de la empresa Strato, Gabinete Arqueológico de Valladolid, a quien debo agradecer los datos con que aquí he contado. 

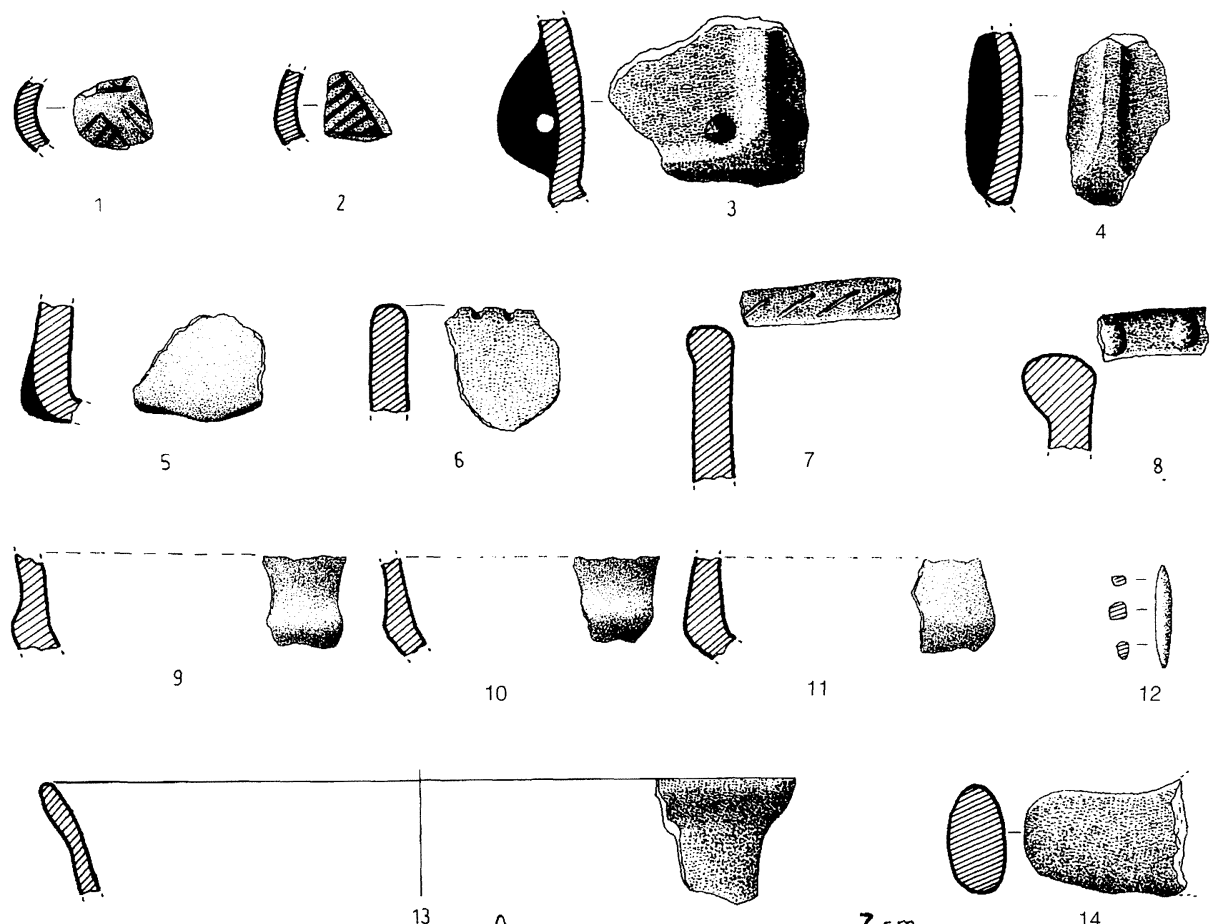

11
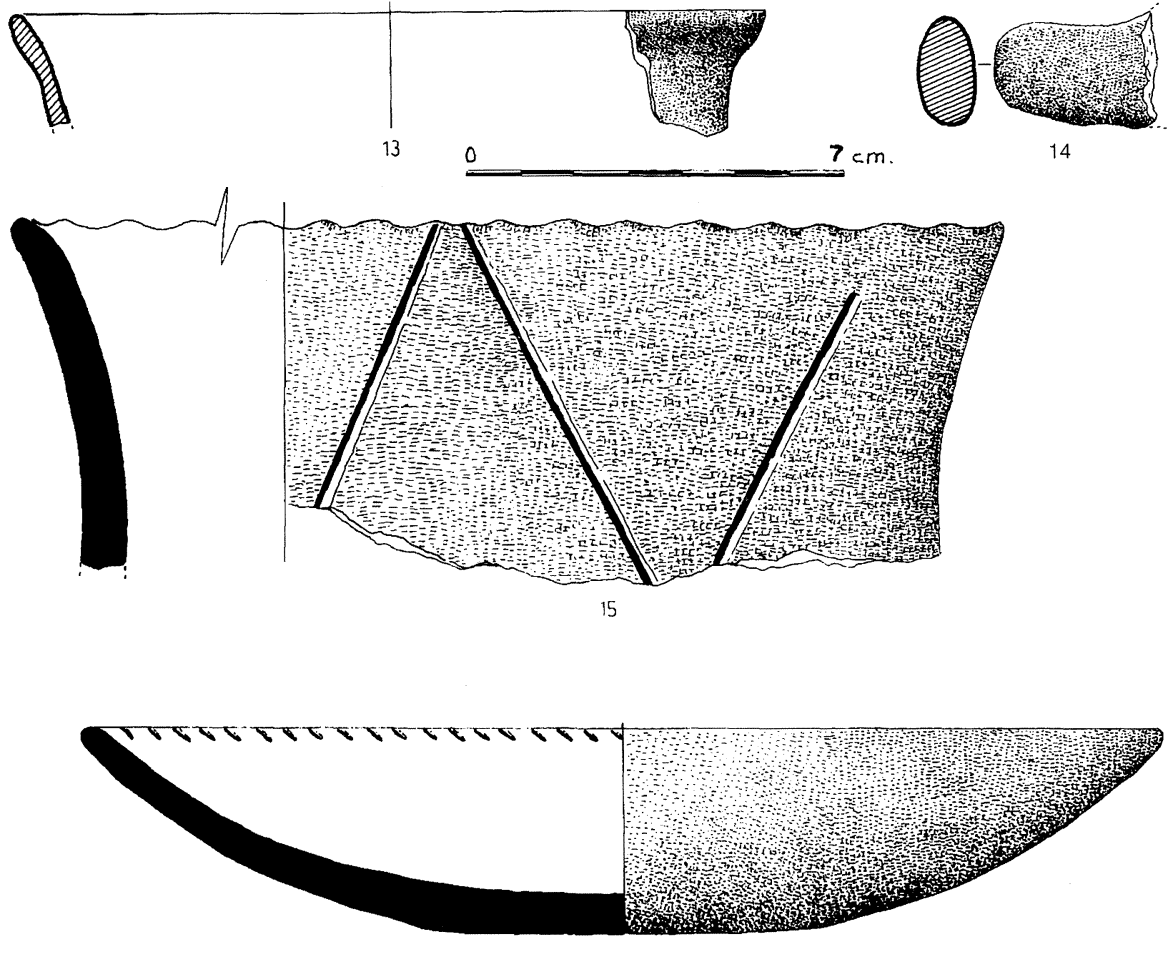

16
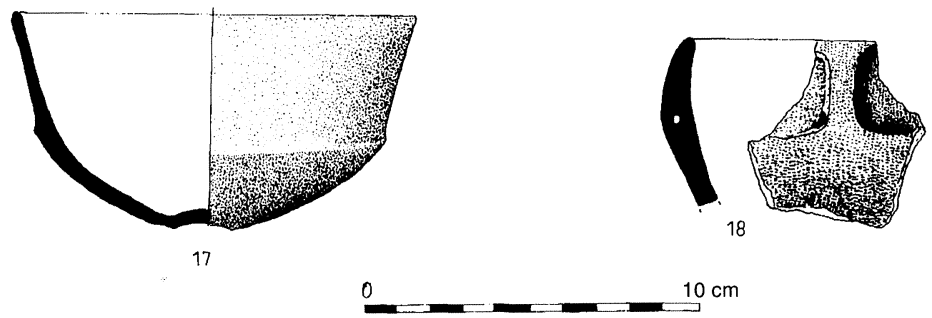

Fig. 3. Guaya (Berrocalejo de Aragona): 1 a 14. Cerro de la Cabeza (Ávila): 15 a 18.

T. P., 56, n. ${ }^{\circ} 2,1999$ 

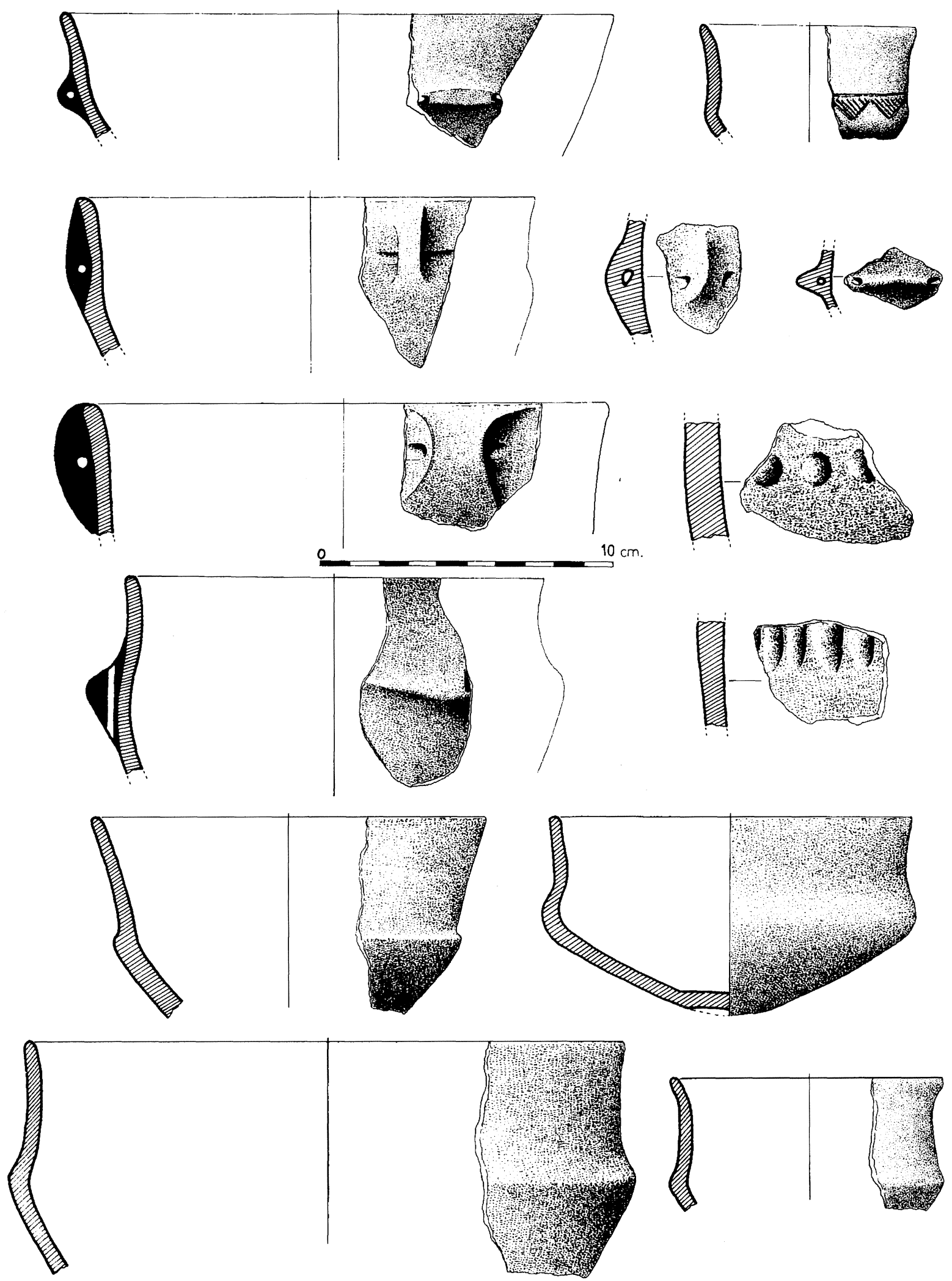

Fig. 4. Las Zorreras (Muñana, Ávila).

T. P., 56, n. ${ }^{\circ} 2,1999$ 
terada. Se mezclan materiales del final del Calcolítico y principios de la Edad del Bronce con otros, más frecuentes, correspondientes a Cogotas I y, todos ellos, a su vez con materiales cuya cronología implica a la fase inicial de la cultura del Soto, momento del que se pudo aislar un punto determinado en el que sólo aparecían cerámicas de este momento y fragmentos de bronce, uno de ellos una aguja. Como en el yacimiento de El Cerro de la Cabeza, interesa especialmente ahora constatar este momento cultural del Soto inicial.

Además de los trabajos de campo en estos dos yacimientos, el reciente descubrimiento de otros seis nuevos en el mismoValleAmblés -La Lomilla (Muñopepe) (Figs.1-2, 5), El Pradillo (Gemuño), LosArenalones (Guareña) (3) y posiblemente también El Cogote II (La Torre) y El Campillo (Gemuño)-y en el inmediato por el Este Campo Azálvaro -Guaya (Berrocalejo de Aragona) y La Solana Angosta (Bernuy-Salinero)- suponen, por el volumen de materiales de superficie que han proporcionado, un conjunto de datos cuyo contenido es una novedad muy digna de tenerse en cuenta. Es importante resaltar, ahora que he aludido a la presencia de estos yacimientos de tipo Soto en el Valle Amblés, la proximidad geográfica que existe entre éstos y Los Castillejos de Sanchorreja, base principal para la formulación de las tesis de González-Tablas.

El Valle Amblés es una unidad geográfica perfectamente definida y delimitada por el relieve (Fig. 1). Una de las altitudes mayores que flanquean el reborde norte de este valle, denominado Sierra de Ávila, es, precisamente, un significativo promontorio a $1.553 \mathrm{~m}$ de altitud (a $460 \mathrm{~m}$ de diferencia con respecto al fondo del valle), que preside la zona final del valle por el noreste en uno de cuyos picachos están enclavados Los Castillejos de Sanchorreja. Los yacimientos aludidos de El Cerro de la Cabeza, Guaya (Figs. 2-3), Las Zorreras (Figs. 2, 4), La Solana Angosta, La Lomilla (Figs. 2, 5) o Los Arenalones (Figs. 2, 6, 7), distan de Los Castillejos en línea recta $10,13,10,4,22$ y $24 \mathrm{~km}$ respectivamente.

\section{EL ESTADO DE LA CUESTIÓN}

J. González-Tablas ha sido quien más se ha preocupado por investigar directamente la etapa inter-

(3) Debo agradecer a su descubridor, Jesús López Jiménez y a Rogelio Muñoz, propietario de las tierras donde se encuentra el yacimiento, ambos vecinos de Guareña, su ayuda en el rescate de materiales de este yacimiento. media entre el Bronce Final y la II Edad del Hierro en el Sur de la Meseta Norte. A través de varios trabajos publicados entre 1983 y 1990 ha ido desarrollando su propia interpretación de la secuencia, chocando ésta con no pocos escepticismos (Martín Valls, 1986-1987: 60-61; Delibes y Romero, 1992: 236-237; Delibes, 1995: 85; Delibes et alii, 1995: 58-59; Castro et alii, 1995: 100-102; Quintana y Cruz, 1996).A principios de los ochenta GonzálezTablas retoma las investigaciones en Los Castillejos de Sanchorreja, iniciadas por Camps y Navascués y publicadas posteriormente por Maluquer de Motes (1958), con nuevas campañas de excavación que se interesan principalmente por el desarrollo de la secuencia cultural y su problemática. En una segunda fase, en 1987-88, continuará excavando en otra zona del yacimiento donde interpreta que se dieron rituales funerarios (González-Tablas, 1990).

Las excavaciones de González-Tablas supondrán primero la verificación de que la estratigrafía hallada por Camps y Navascués y su agrupación en dos momentos sin hiatus alguno-Sanchorreja I o Inferior y Sanchorreja II o Superior- es cierta como evidencia morfológica del registro arqueológico. Encuentra tres momentos: el más reciente, denominado Sanchorreja Superior, representado por los niveles III y IV, con cerámicas a peine, pintadas bícromas abundantes y a torno pintadas con bandas paralelas en el borde, además de fíbulas de doble resorte, cuchillos de hierro, hachas planas y puntas de lanza. A diferencia de Camps y Navascués, a juzgar por lo escrito por Maluquer de Motes (1958: 64), González-Tablas sólo halla las cerámicas bícromas y las fíbulas de doble resorte en Sanchorreja Superior, ligadas a las cerámicas a peine. Sin solución de continuidad, tanto para él como para Camps y Navascués, antecede a lo anterior el nivel V (nivel $d$ y $e$ de Camps y Navascués), atribuible al Bronce Final Cogotas I. Es el denominado Sanchorreja Inferior. Debajo de éste, pero sólo en la zona alta, se encuentra otro, no documentado en las excavaciones antiguas, del que dice contener cerámicas lisas (González-Tablas, 1989: 118).

Un detalle de la base empírica parece quedar claro en los trabajos de campo antiguos y recientes de Los Castillejos: la no interrupción morfológica de la secuencia estratigráfica entre el Bronce Final y la Edad del Hierro, por tanto la aparente continuidad habitacional entre ambas fases, continuidad que admite Maluquer de Motes (1958: 93), si bien interpretando que la ruptura en la cultura material puede ser debida a un posible dominio exterior o 

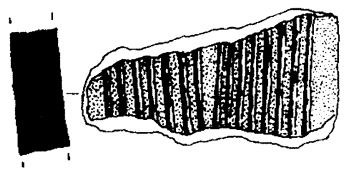

\section{(10}
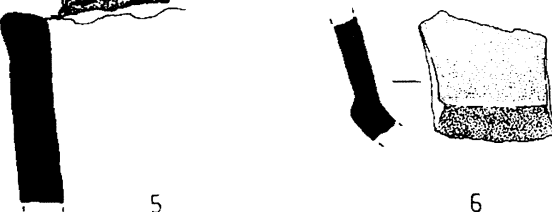

6
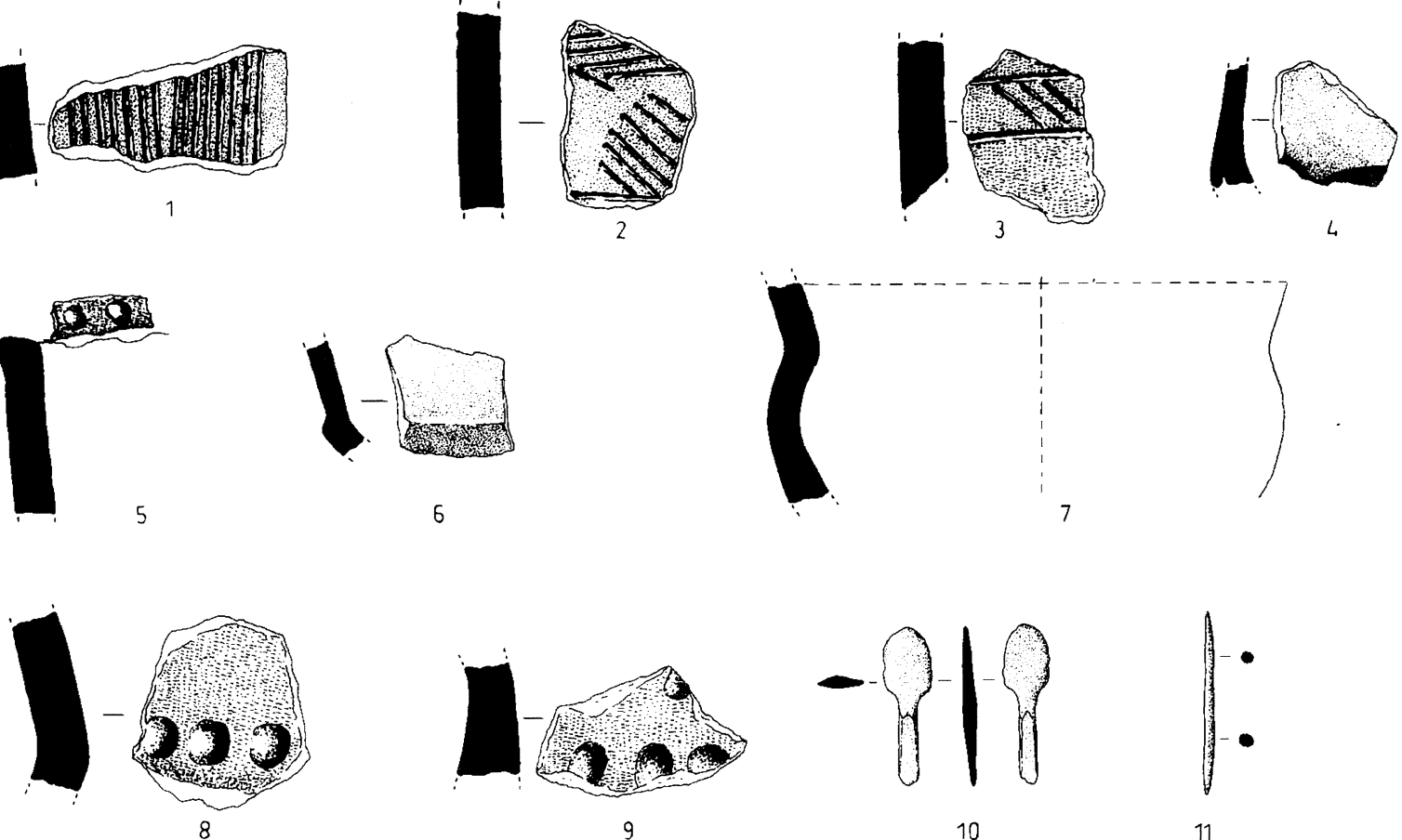
$6 \mathrm{~cm}$
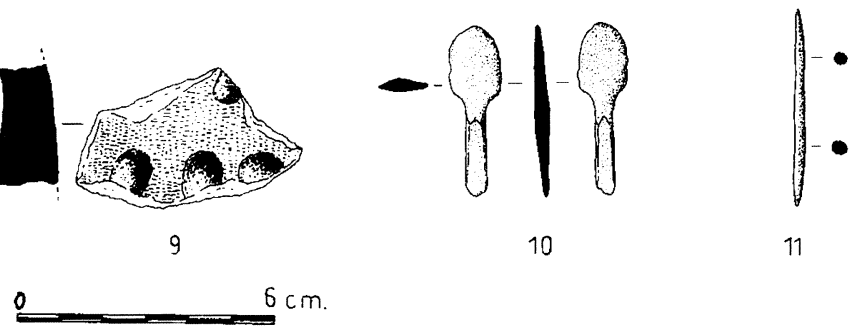

11
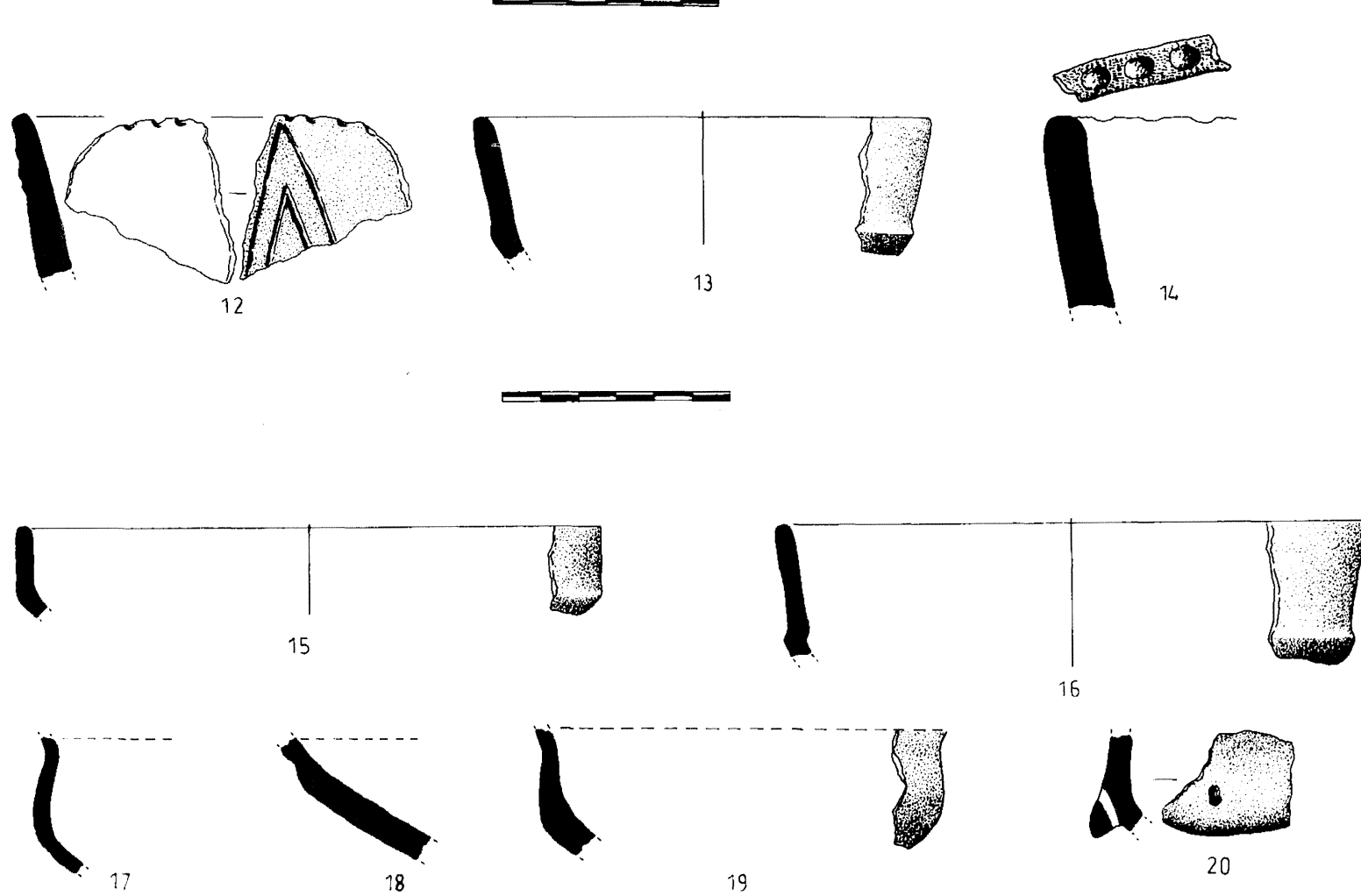

19

16 0 $10 \mathrm{~cm}$

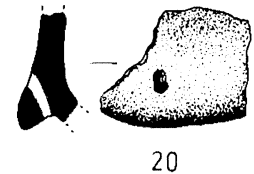
20

Fig. 5. La Solana Angosta (Bernuy-Salinero, Ávila): 1 a 11 La Lomilla (Muñopepe, Ávila): 12 a 14 La Iglesia (Cisla, Ávila): 15 a 20.

T. P., 56, n. ${ }^{\circ} 2,1999$ 

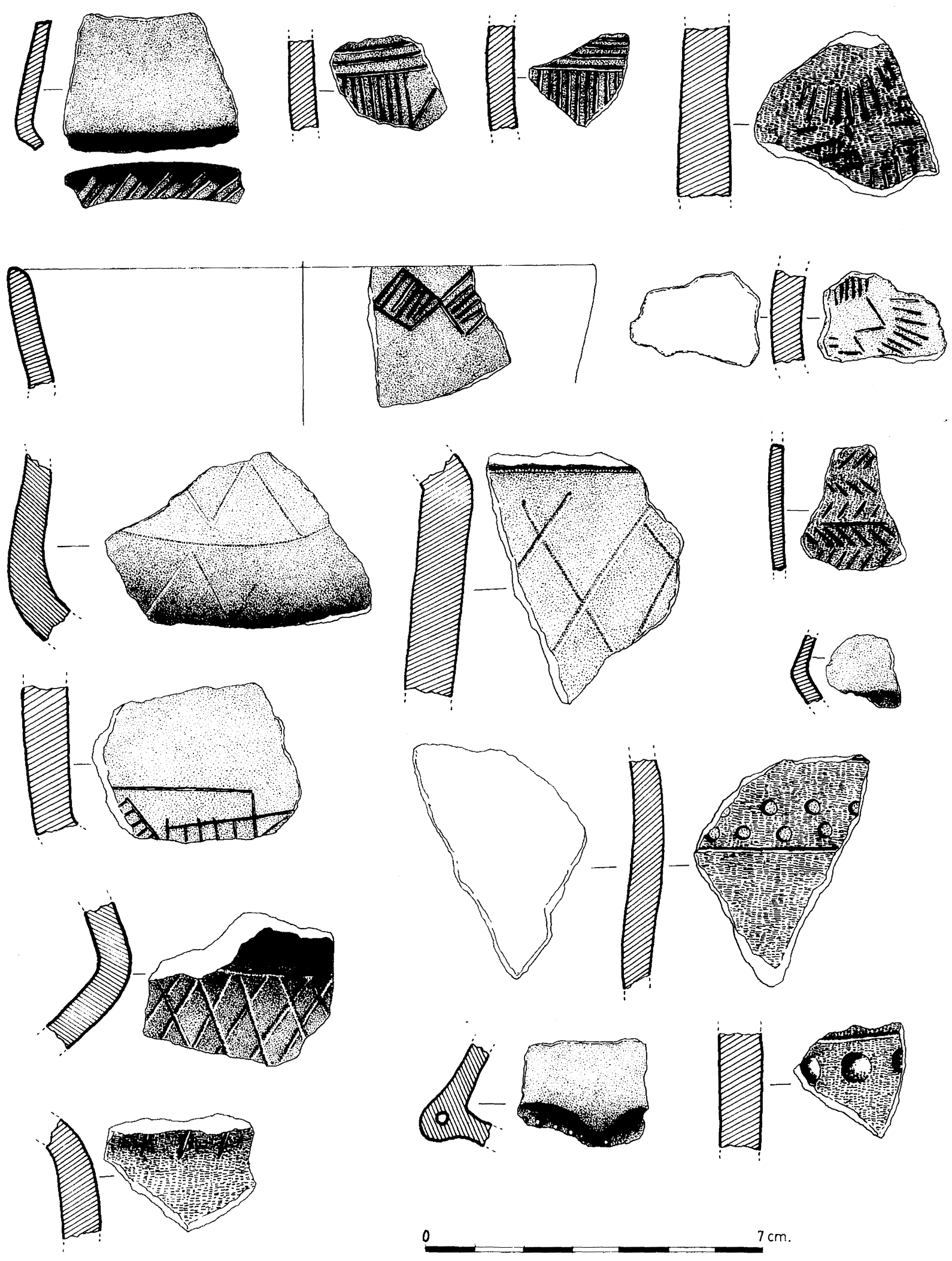

Fig. 6. Los Arenalones (Guareña, Ávila).

T. P., 56, n. ${ }^{\circ} 2,1999$ 
influencia que posibilita el cambio. Previsiblemente, de la continuidad estratigráfica parta la primera certeza de González-Tablas (1990: 71) para considerar, en primer lugar, como Maluquer de Motes, que no hay ruptura entre Sanchorreja Inferior y Sanchorreja Superior, entre Cogotas I y las cerámicas a peine y, en segundo lugar, que los niveles superiores corresponden al Hierro I.

Además de la evidencia estratigráfica, GonzálezTablas apunta con más énfasis otras adicionales y coincidentes con la esencia de la anterior: el factor morfológico diferencial aportado por las cerámicas a peine de Sanchorreja que, a su entender, suponen un estadio inmediatamente anterior a las cerámicas a peine características del horizonte Cogotas II en la Meseta Norte. Denomina a este estadio Sanchorreja II o Cogotas IIa, le da una cronología de arranque cuando menos del 650 a.C. y lo cree paralelo al Soto II del centro de la cuenca del Duero. Con ello se muestra partidario de la existencia en ese momento de dos culturas paralelas en la Meseta Norte: Sanchorreja II y Soto II, con interrelación, sobre todo de la primera en la segunda. Ello le lleva, por una parte, a poner en duda su verdadera entidad, ya que hay bastantes yacimientos de ese momento en el valle del Duero en los que se dan cerámicas representativas de Sanchorreja II: las cerámicas a peine de tipo antiguo, las que se han denominado también de la fase Cogotas II $a$. Observa, por otra parte, una importante falta de tipismo en esas cerámicas de Sanchorreja, que atribuye a su carácter arcaico, por ejemplo los soportes formales, que reflejan la influencia de los Campos de Urnas delValle del Ebro (González-Tablas, 1990: 64) o en la decoración interior de los vasos, a los que vincula con el Bronce Final, que culturalmente les antecedería, como la estratigrafía de Los Castillejos habría dejado patente en las excavaciones antiguas y en las modernas. Por tanto Sanchorreja II, según la opinión de González-Tablas, surgía como germen prematuro de Cogotas II y lo hacía a partir de la raíz tardía y perdurada de Cogotas I cien años más tarde de lo corriente en zonas limítrofes. Sanchorreja II alcanzaría desde principios del siglo VII a.C., a partir de la cronología de un botón cónico, hasta comienzos del sigloV a.C., como indicarían las cerámicas a torno antiguas del yacimiento (González-Tablas, 1990: 66).

Si bien en la estratigrafía de Sanchorreja no falta nada o no parece faltar nada, como tendría que significar la evidencia mostrada por dos excavaciones distintas en dos épocas distintas y dos lugares también distintos del yacimiento, ese espacio de tiempo de aproximadamente un siglo tendría que estar justificado por la perduración de Cogotas I hasta el 700 a.C., un siglo más de lo que se admite por la mayoría de los investigadores. Tendría que haber perdurado en las sierras del Sur de la Meseta Norte, hipótesis que se ha esbozado en más de una ocasión ante la falta de datos para negarlo.

Para González-Tablas las cerámicas a peine de Sanchorreja son anteriores a las similares en técnica de la Meseta Norte, constituyen su precedente y representan el Hierro I de esa zona. Este momento es asociable a lo conocido en otros yacimientos como los salmantinos de El Picón de la Mora (Cerralbo) o El Cerro de San Vicente (Salamanca), situados más al Oeste de la zona que venimos tratando.Todos ellos representarán en el Sur de la Meseta Norte un mundo paralelo a la cultura del Soto de Medinilla en el centro de la cuenca del Duero (González-Tablas, 1990: 69), dándose la influencia de ambas facies del Hierro I en el Cerro de SanVicente de Salamanca como zona de transición (González-Tablas, 1989). Para ratificar su teoría, el citado autor analiza las secuencias más completas de la zona sedimentaria. Una de las estratigrafías más próximas y que mejor cuadran con sus postulados es la aportada por M. García y M. Urteaga (1985) en El Castillo de la Mota, en Medina del Campo. Esta estratigrafía es interpretada a favor de sus tesis considerando un hecho evidente y problemático: la presencia de cerámicas a peine en toda la secuencia del yacimiento, cuyo inicio se atribuye al Soto I (nivel II-3: 800-650 a.C.), siguiendo con el Soto II (Nivel II-2: 700/650-550 a.C.) y por último el nivel II-1, fechable entre el 550-400 a.C., que los excavadores atribuyen a un momento antiguo de Cogotas II (Cogotas IIa). La presencia de cerámicas a peine en la estratigrafía de La Mota desde el inicio (800-650 a.C.) ratifica las tesis de González-Tablas (1990: 69) haciendo contemporáneas, paralelas e interrelacionadas las culturas del Soto y Sanchorreja II.

Desde que González-Tablas expusiera su teoría hasta el presente se ha mantenido una importante controversia entre los investigadores de estas etapas en la Meseta Norte, centrada fundamentalmente en la aparición y origen de las cerámicas a peine y en la posible perduración de la Cultura de Cogotas I en el Sur de la Meseta Norte. R. Martín Valls (198687) veía una cierta indefinición en esta zona y consideraba esencial para la clarificación del problema la estratigrafía de Sanchorreja, cuya sucesión tal y como quedaba marcada por el registro arqueológico, a nadie le cuadraba. Es decir o sucedía algo se- 
dimentológicamente nada claro o en Sanchorreja Superior los niveles mostraban alguna alteración que producía la confusión. Era evidente que entre Sanchorreja Inferior y Sanchorreja Superior había una ruptura cultural presumiblemente motivada por una causa importante, bien una influencia externa, como la indicada por Maluquer de Motes, o bien por la transición insinuada por González-Tablas (las primeras cerámicas a peine decoradas al interior, localización similar a la de sus antecesoras de Cogotas I...), o por la apuntada por R. Martín Valls (1986-87: 60). Este admite la existencia de un hiatus entre Sanchorreja Inferior y Superior, situando entre ambos momentos las cerámicas hallsttáticas que Maluquer de Motes coloca en los dos, así como las fíbulas de doble resorte, que González-Tablas sólo encuentra en el Superior.

Interpreto que la propuesta de Martín Valls presupone una alteración en la estratigrafía por la cual no se distingue con claridad ese nivel transicional que él propone como intermedio hasta las cerámicas a peine, cuyo inicio sitúa hacia el 500 a.C., representando el principio de la II Edad del Hierro. Martín Valls (1986-87: 60) confiaba entonces que futuras investigaciones en el propio yacimiento de Los Castillejos de Sanchorreja o en Las Cogotas harían reconocer en la zona un nivel de transición a las cerámicas a peine tipo Soto o similar. No admitía, por tanto, las teorías de González-Tablas creyendo, además, que las cerámicas a peine marcarán en Sanchorreja el inicio de la II Edad del Hierro (hacia el 500 a. C.), coincidente con el fin del Soto II en el centro de la cuenca del Duero. En esa zona es, por otra parte, donde empiezan las primeras cerámicas de este tipo, como quedaría patente a través del C-14 en el yacimiento de El Castillo de la Mota, en Medina del Campo, no así en el registro arqueológico, ya que aparecen en la secuencia desde el principio - nivel II-3, entre el 800 y el 650 a.C.- al final (García y Urteaga, 1985: 134). Claro que nada impide pensar que estén más próximas a la fecha más reciente del nivel. Ello cuadraría mejor con la tesis de González-Tablas para esas cerámicas en Sanchorreja Superior, cuya cronología inicial sitúa en torno a la mitad del siglo VII a.C. De todos modos es necesario que los datos aportados por la secuencia de La Mota queden ratificados por nuevos trabajos con estratigrafías de potencia similar.

$\mathrm{Al}$ no haberse producido nuevas investigaciones de campo en el sector suroriental de la Meseta Norte, la cuestión ha permanecido estancada durante una década sin que se modificaran las posturas, siempre basadas sobre la misma base empírica. Pero a medida que se ha abordado de forma general la Edad del Hierro, otros autores han manifestado sus dudas acerca de las teorías de González-Tablas (Delibes y Romero, 1992: 236-237; Delibes et alii, 1995: 5859; Castro et alii, 1995: 100-102). Concretamente Delibes (1995), en un trabajo que contempla todos los datos existentes hasta ese momento para abordar la Prehistoria reciente de Ávila, considera que lo más prudente es esperar nuevos datos, mostrándose escéptico sobre la existencia de culturas residuales, como tendría que ser el caso de Cogotas I en el Sur de la Meseta Norte, según González-Tablas.

Precisamente la intención de este artículo es aportar esos nuevos datos, contribuyendo a la definitiva clarificación de la secuencia y, al menos, a una parte del problema, aunque queden aún ámbitos o aspectos muy concretos por clarificar, como la tipología antigua, según González-Tablas (1989), de'las cerámicas a peine de Sanchorreja con respecto a las más típicas y habituales que aparecen en el centro y en el Sur de la Meseta Norte.

\section{LOS NUEVOS DATOS}

Los trabajos para el Inventario Arqueológico de Ávila por una parte, algunos hallazgos casuales y el resultado de determinadas excavaciones de urgencia, muestran ahora un espectro de datos mucho más amplio y variado y, sobre todo, más acorde con una realidad que ya había sido verificada en otras zonas de la Meseta Norte, como en el centro de la cuenca del Duero. A través de lo que conocemos actualmente y expondré a continuación, estamos en disposición de extender, al menos hasta el sector sureste de la Meseta Norte, la secuencia cultural conocida para el Duero Medio, con sus mismos componentes. Es decir que la estratigrafía de Los Castillejos de Sanchorreja y, también, por lo que le toca de similaridad, la de Las Cogotas, no son el fiel reflejo de la realidad diacrónica sucedida desde el Bronce Final hasta la II Edad del Hierro. Considerar que en tan restringido territorio pudiera darse una dualidad de procesos evolutivos, con yacimientos en los que Cogotas I perdura y otros, al lado mismo, sincrónicos pero culturalmente distintos, sería sin duda forzar la interpretación de una realidad que parece mucho más simple.

Si durante un tiempo la firmeza y doble confirmación de la estratigrafía de Los Castillejos pudo ser una razón a la que aferrarse como base, apoyán-

T. P., 56, n. ${ }^{\circ} 2,1999$ 
dose, además, en la falta de otros datos empíricos que lo negaran, se vuelve ahora a la inversa con la aparición de esos datos. Es decir, parece necesario buscarle una explicación en Los Castillejos a la falta de un nivel de interposición entre la fase Inferior y la Superior, entre Cogotas I y Cogotas II representada allí, porque la realidad confirmada es otra y pone claramente en entredicho aquel proceso mostrado por una estratigrafía, que tiene que estar necesariamente incompleta. Posiblemente la explicación de esa estratigrafía sea la actuación de determinados procesos geológicos o geo-antrópicos que eliminaron el nivel arqueológico o estéril intermedio entre ambos momentos. Ese nivel curiosamente estaría presente en la Plaza de San Martín de Ledesma aunque, al parecer, según sus excavadores (Benet et alii, 1991: 119) bastante alterado a causa de posibles tareas de terraplenado.

Por el momento conocemos 14 yacimientos adscribibles al Hierro I en la provincia de Ávila y uno, al menos, en el Este de la provincia de Salamanca, sin contar con los datos antiguos y modernos sobre el particular aportados por las excavaciones en la ciudad de Salamanca. Todos los de Ávila se encuentran al Norte del macizo de Gredos. Sin duda no son los únicos. De hecho algunos de ellos han sido identificados como tales a través de la revisión de los materiales de muestra recogidos por los prospectores y depositados en el Museo de Ávila (4).

A grandes rasgos podemos distinguir cuatro tipos de yacimientos entre los que novedosamente aporta este trabajo:

1. Asentamientos en los que aparecen conjuntamente materiales correspondientes a Cogotas I y al Soto inicial. Representados por El Cerro de la Cabeza (Ávila) y Las Zorreras (Muñana) (Figs. 1-4). Cuando se trata de cerámicas son de tipo tosco, grandes recipientes decorados con cordones digitados o labios incisos o impresos y, en ocasiones, con acanaladuras. Con éstas aparecen también cerámicas de pequeña capacidad, con pastas muy finas y superficies bruñidas, carenadas, decoradas con finas incisiones y adornadas con asas que parecen conseguidas por medio de un pellizco o pequeño mamelón perforado en la pasta, características inequívocas de este momento en todos los yacimientos conocidos y con paralelos en el Duero Medio (Quintana y Cruz, 1996; Balado, 1989). Paralela-

(4) Debo agradecer a don Manuel Santonja, Director del Museo de Salamanca y a doña María Mariné, Directora del Museo de Ávila las facilidades dadas para el estudio de estos materiales depositados en los citados museos. mente se encuentran con cierta frecuencia piezas de bronce. Ambos yacimientos están ubicados en el borde mismo del Valle Amblés, en una situación coincidente con lo que es el hábitat prototípico de los yacimientos calcolíticos allí mismo, sin preocupación defensiva. Simplemente parece buscarse el abrigo respecto a las inclemencias que vienen por el Norte a estas tierras frías abulenses.

2. Yacimientos donde exclusivamente aparecen materiales correspondientes al Soto inicial, como Los Arenalones (Guareña) (Figs. 1-2, 6-7), Guaya (Berrocalejo de Aragona) (Figs. 1-3) y El Pradillo (Gemuño), todos en Ávila. Se diferencian de los del grupo anterior en que no aparecen cerámicas de Cogotas I. El resto de la cultura material es la propia del Hierro I con una extraordinaria proliferación de cerámicas muy finas, carenadas y decoradas a veces con finas incisiones. La metalurgia de bronce está preșente siempre. Del Pradillo se conoce una punta de largo pedúnculo y aletas. En LosArenalones es abundante con punzones, agujas, la punta de un puñal y frecuentes restos de fundición, como en Guaya donde, además, apareció un pequeño punzón. Los análisis realizados por el Dr. Salvador Rovira (5) confirmaron que siempre se trataba de bronce. Estos datos parecen indicar que la metalurgia del bronce sigue teniendo un peso específico muy importante, pareciendo ausente la del hierro. Están enclavados en lugares sin ninguna defensa natural, puede.decirse que todo lo contrario. Uno y otro están al lado de cursos de agua estacionales, sobre suaves laderas, en zonas con pastos que gozan de agua subterránea capaz de retardar el habitual agostamiento de los pastos al inicio del verano. En torno a LosArenalones es posible la práctica de la agricultura además de la ganadería. En el de Guaya es la ganadería, al parecer, el único recurso adecuado a las circunstancias naturales de su entorno.

3. Yacimientos en los que los materiales parecen corresponder al Soto I avanzado, tal vez en la transición al Soto II. El Torrejón (Alba de Tormes, Salamanca) (Fig. 8), La Solana Angosta (BernuySalinero) (Figs. 1-2,5) y Prados Galindos (Cabizuela), ambos en la provincia de Ávila.Todos ellos tienen un número suficiente de materiales estudiables con garantía para su catalogación cultural. Probablemente con ellos deban ser incluidos también El Campillo (Gemuño), El Cogote II (La Torre), El Rompido de las Berlanas (Hernansancho), La Lo-

(5) Departamento de Conservación. Museo Arqueológico Nacional. Serrano, 13. 28001 Madrid. 

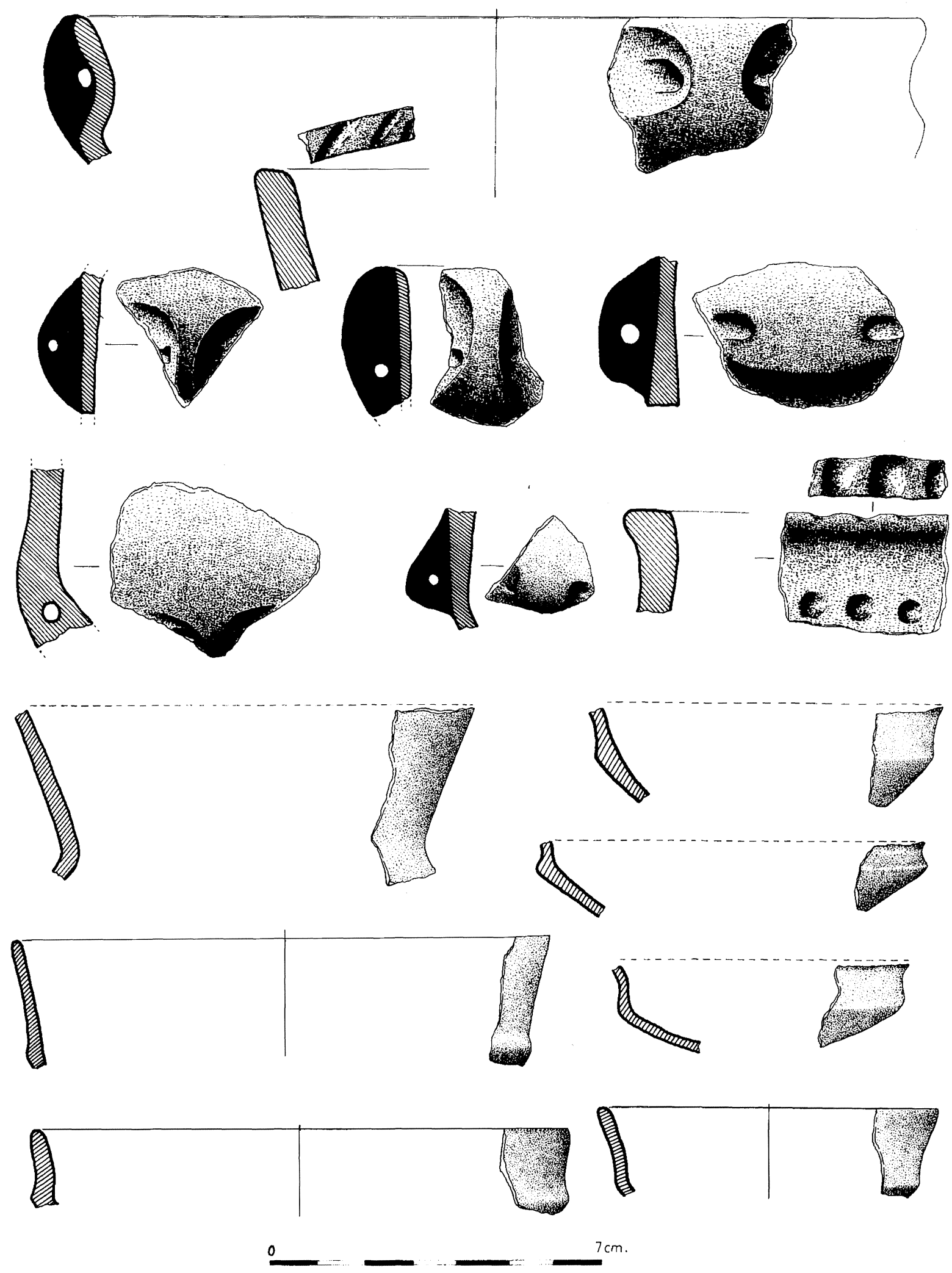

Fig. 7. Los Arenalones (Guareña, Ávila).

T. P., 56, n. ${ }^{\circ} 2,1999$ 

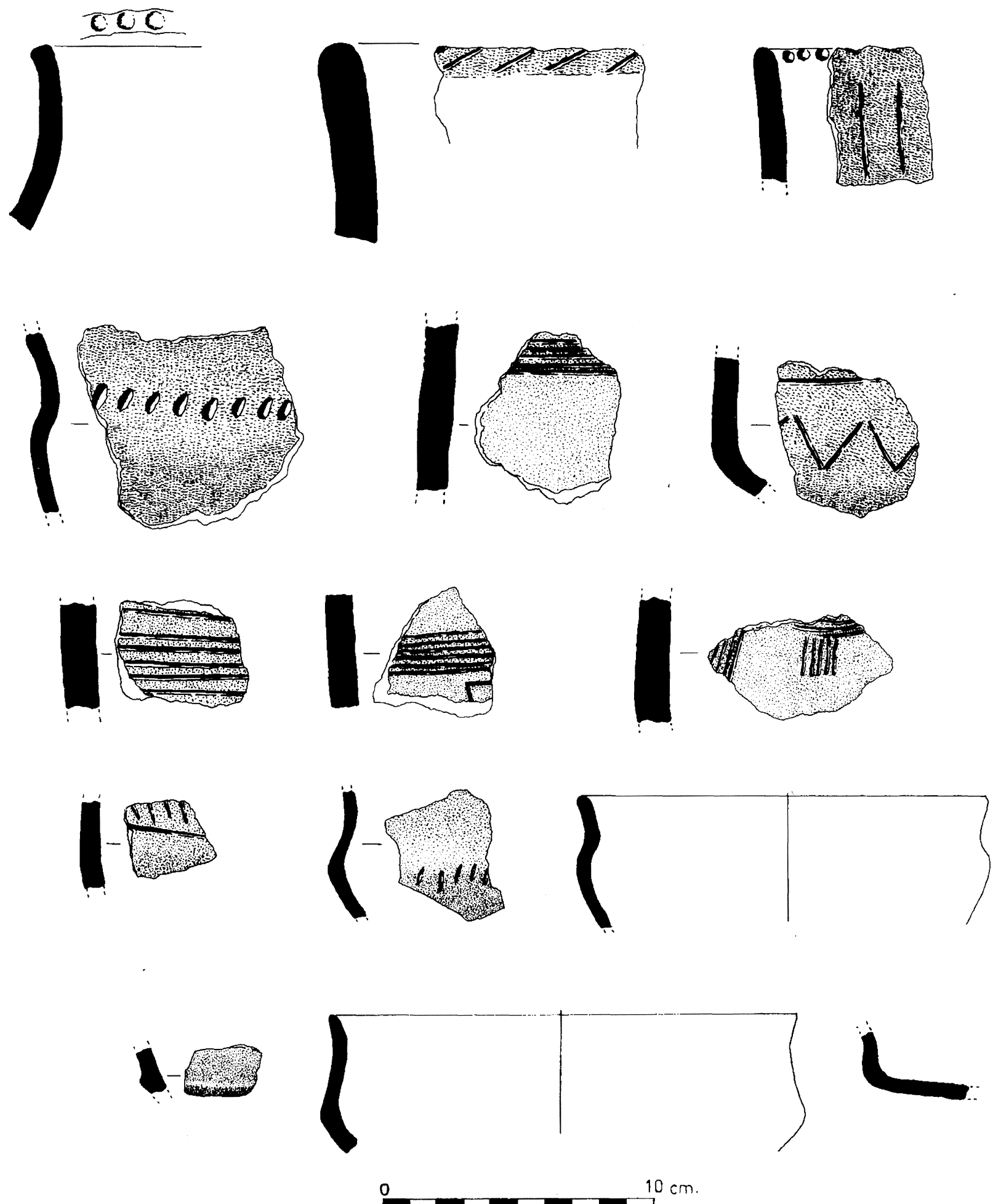
$10 \mathrm{~cm}$.

Fig. 8. El Torrejón (Alba de Tormes, Salamanca). 
milla (Muñopepe) (Figs. 1-2, 5), Cerro de la Horca y Los Guijares (Mirueña de los Infanzones), Cerro del Río (Mesegar de Corneja) y El Gualdar (El Oso), todos ellos en Ávila. Presentan entre los materiales de prospección elementos del Hierro I, pero insuficientes por ahora para encuadrarlos con claridad dentro de un momento concreto. Por lo que sabemos aquí las asas de pellizco o mamelón perforado disminuyen, lo mismo que los vasitos con finas incisiones. Se mantienen las cerámicas finas, bruñidas y carenadas y los labios y cordones incisos y/o impresos y digitaciones y/o ungulaciones en el cuerpo de las piezas, siempre ligadas a recipientes más toscos que los referidos vasitos. Son poblados poco extensos, ubicados, como los de los tipos anteriores, en lugares sin defensas naturales, ya sea en el reborde de un valle o en zonas llanas sobre suaves laderas al borde de arroyos poco importantes o en el entorno de zonas lagunares de las que abundan al Norte de Ávila. La Solana Angosta está en medio de un páramo húmedo en el que el aprovechamiento potencial parece ser más el ganadero que el agrícola, posiblemente un modelo económico aplicable a los restantes yacimientos mencionados anteriormente.

4. Yacimientos con materiales que, en su conjunto, parecen apuntar al Soto II y a los inicios del Hierro II. Conocemos solamente el caso de El Castillo Bayuela (Hoyorredondo, Ávila) (Figs. 2, 9) y es importante su existencia en la zona para plantear algunas hipótesis sobre el desarrollo de la Edad del Hierro. Se encuentra en el Valle del río Corneja, afluente del Tormes en el inicio de su curso medio, a tan sólo $16 \mathrm{~km}$ de los conocidos poblados de la II Edad del Hierro de Las Paredejas y Los Tejares, ambos englobados dentro del complejo arqueológico conocido como Cerro del Berrueco (Fabián, 1985). El Castillo Bayuela tiene una superficie en torno a las 2 ha. Está situado en una terraza ligeramente elevada sobre el río Corneja, en un punto aparentemente sin buenas condiciones defensivas naturales ni indicios de defensas artificiales, aunque llama la atención el topónimo (Castillo...), tal vez indicativo de algún tipo de defensa desaparecida para facilitar el cultivo que se lleva a cabo actualmente en todo el área del yacimiento. Sin estar dotada la zona de grandes condiciones económicas, puede desarrollarse la agricultura en los alrededores, a la vez que la inmediata vega del río puede proporcionar humedad suficiente para crear pastos hasta entrado el verano. Los materiales conocidos permitirían situarle a grandes rasgos en la transición de la I a la II Edad del Hierro, en la etapa que se ha denominado Cogotas IIa. Hay cerámicas decoradas a peine antiguo (Martín Valls, 1986-87), algunas a torno muy finas, minoritarias entre el grueso de la vajilla, cerámicas a mano con estampillados muy simples, vasitos con pintura roja, cuentas de pasta vítrea y algunas cerámicas cuyas finas incisiones recuerdan a las decoraciones del momento de transición entre el Bronce Final y el Hierro I en el vecino Valle Amblés y en todo el centro del Valle del Duero.

La secuencia cultural del yacimiento por sí misma no importa tanto ahora, como su propia existencia, representante, al menos, del final de la IEdad del Hierro en esa zona y de los momentos iniciales de la II Edad del Hierro tan elocuente en losoppida de Las Paredejas (16 km al Oeste), La Mesa de Miranda (Chamartín, Ávila, a 44 km), Las Cogotas (a 60 $\mathrm{Km}$.) o el propio de los Castillejos de Sanchorreja (a $60 \mathrm{~km}$ ) (Ruiz Zapatero y Álvarez Sanchís, 1995). Quizá pueda ser considerado un prototipo del momento inmediatamente anterior a la agrupación de la población en esos oppida ubicados en lugares altos, reforzados con importantes defensas artificiales que deben ser el indicador del status reinante y en el que se han producido transformaciones de todo tipo capaces de generar un nuevo ambiente cultural y social. Yacimientos como El Castillo Bayuela ratificarían la teoría generalmente admitida de que, a partir de fines del siglo $\mathrm{V}$ a.C., se construyen los castros abulenses y salmantinos en detrimento de poblados como aquél. Sin embargo habría que aclarar la cuestión de si esos oppida son los yacimientos-tipo de ese momento y los únicos que existen, o hay otros menos evidentes, en lugares de menor referencia para el prospector, por ejemplo en llanura. Hasta ahora no se conocen a pesar de estar finalizado el Inventario Arqueológico de Ávila, si bien a un nivel de prospección arqueológica selectiva.

Por tanto, la etapa que seguiría al momento representado por El Castillo de Bayuela sería la de los grandes castros abulenses, incluido el de Los Castillejos de Sanchorreja, cuyo inicio podría ser contemporáneo de aquel, como probablemente también lo sea el de Las Paredejas, dentro del complejo arqueológico de El Cerro del Berrueco (Fig. 10).

\section{CONCLUSIONES A PARTIR DEL NUEVO REGISTRO ARQUEOLÓGICO}

Las novedades mostradas por el registro arqueológico actual implican un cambio sustancial respec- 

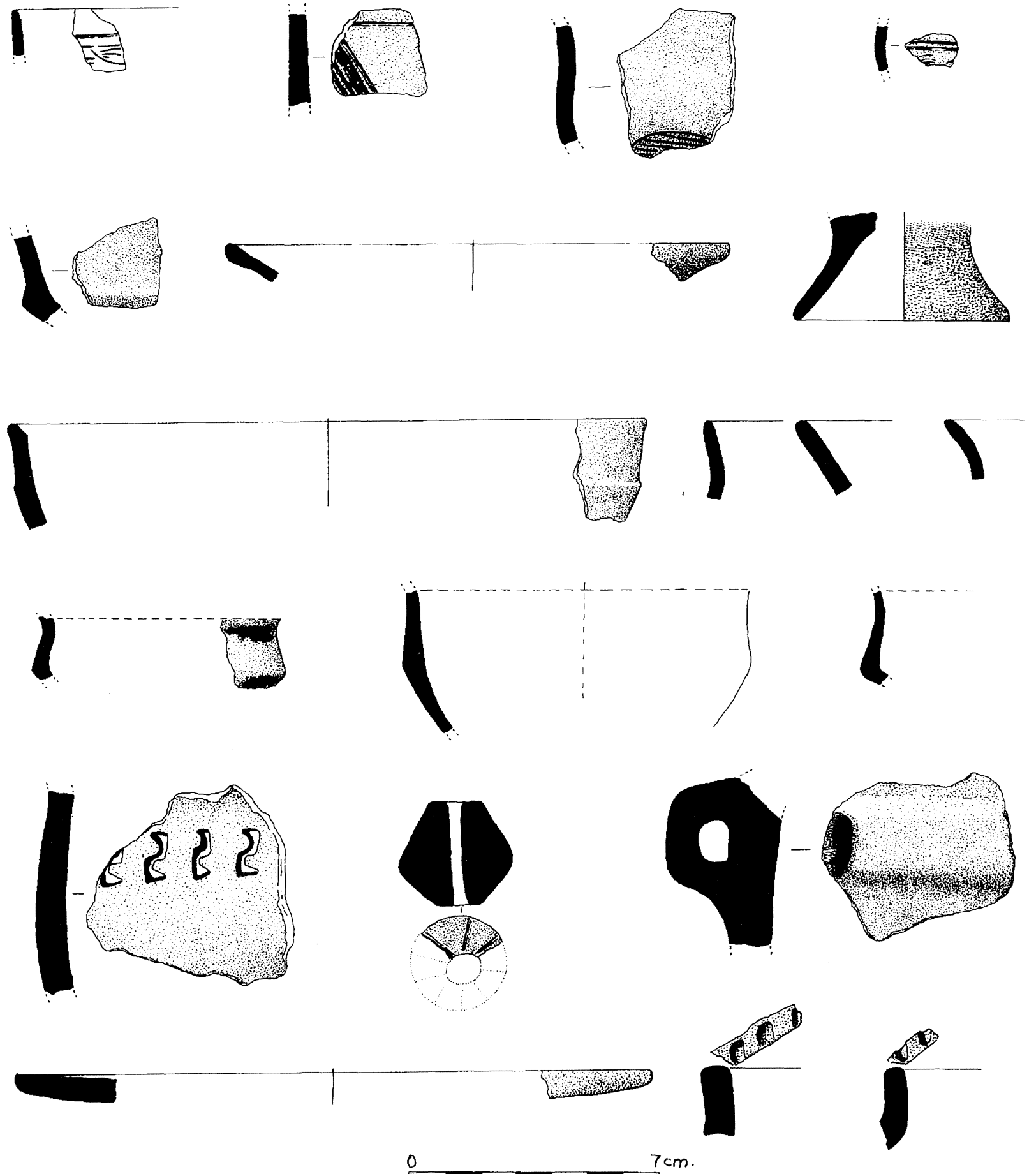

Fig. 9. Castillo Bayuela (Horroyedondo, Ávila).

to a lo que se conocía hasta la fecha en el Sur de la Meseta Norte. En primer lugar, asocian culturalmente estas tierras montañosas (o al menos las surorientales) al paisaje cultural y arqueológico del centro del valle del Duero, más extensamente estudiado y referencia obligada por proximidad geográfica y similitud cultural. En segundo lugar, esa novedad en el registro arqueológico tiene que implicar 


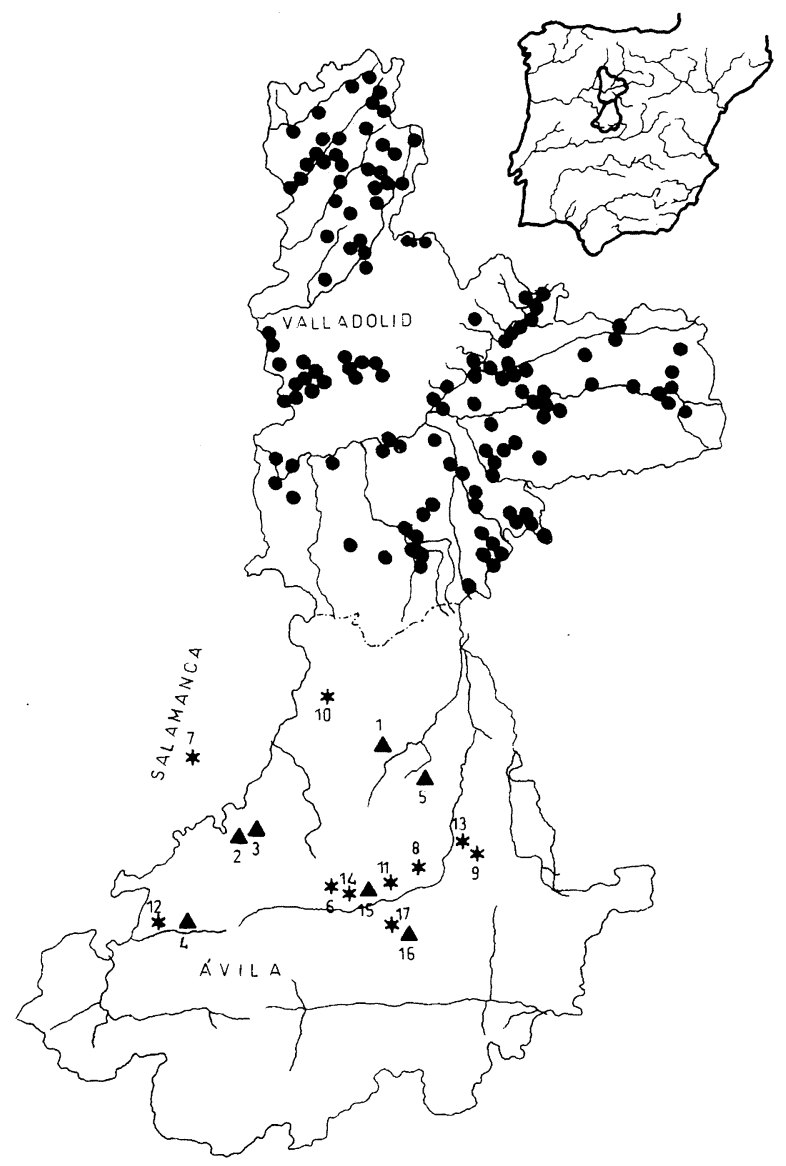

Fig. 10. Yacimientos correspondientes al Hierro I en las provincias de Ávila, Valladolid y Este de Salamanca.

- Yacimientos tipo Soto de Medinilla en Valladolid (Quintana y Cruz, 1996: 49). * Yacimientos tipo Soto inéditos en Ávila. $\Delta$ Posibles yacimientos de tipo Soto de Ávila.

1 Prados Galindos (Cabizuela); 2 Los Guijares (Mirueña); 3 Cerro de la Horca (Mirueña); 4 Cerro del Río (Mesegar de Corneja); 5 El Guialdar (El Oso); 6 Las Zorreras (Muñana); 7 El Torrejón (Alba de Tormes, Salamanca); 8 Cerro de la Cabeza (Ávila); 9 La Solana Angosta (Bernuy-Salinero); 10 La Iglesia Vieja (Cisla); 11 La Lomilla (Muñopepe); 12 Castillo Bayuela (Hoyorredondo); 13 Guaya (Berrocalejo deAragona); 14 Los Arenalones (Guareña); $15 \mathrm{El}$ Cogote II (La Torre); 16 El Campillo(Gemuño); 17 El Pradillo (Gemuño).

necesariamente la revisión de los planteamientos de González-Tablas sobre la transición del Bronce Final a la Edad del Hierro y su idiosincracia. La evidencia de los materiales, aunque una parte sean producto de prospecciones superficiales, parece innegable: existe una etapa siguiente al Bronce Final Cogotas I cuyos materiales más representativos son, sobre todo, los pequeños recipientes cerámicos con frecuencia carenados de pastas muy finas y cuidadas, reductoras y bruñidas, a veces adornados con mamelones perforados y con asas muy características. La documentación obtenida ahora permite intuir, con todas las garantías y con paralelos suficientes, una fase de transición entre Cogotas I y el Hierro I que en algunos casos aparece representada a través de materiales de ambos momentos y en otros sin cerámicas de Cogotas I. El desconocimiento de las claves de la transición impide por el momento saber si estos yacimientos suceden a los anteriores o son paralelos.

En cualquier caso Cogotas I es sustituida en un determinado momento por otra cultura cuyas manifestaciones tienen paralelos muy claros y amplios en, al menos, la mitad meridional de la Península Ibérica, Levante y el Valle del Ebro. Claros delatores de ese cambio son los vasitos carenados y las decoraciones incisas, muchas veces ligadas a aquéllos y tan característicos de buena parte de la Península Ibérica -sureste, Baja Andalucía, Valle del Ebro, Extremadura y centro de Portugal- (Balado,1989; Romero, 1980). Estos vasitos parecen determinantes para situar la transición entre el Bronce Final y el Hierro I, aunque la cronología general de su uso conoce algunas fluctuaciones, posiblemente por la falta de investigación sistemática y de conjunto en algunas zonas en las que desde hace no mucho tiempo son novedad. Se dan fechas más altas o más bajas en función de los paralelos y asociaciones, algo lógico si tenemos en cuenta que estarían en uso durante un tiempo. Interesa aquí fundamentalmente el hecho de que constituyen, al menos en todas las zonas señaladas más arriba, la transición de la Edad del Bronce a la del Hierro y los primeros momentos de ésta, si nos atenemos, por ejemplo, a las fechas dadas para ellas en yacimientos bien conocidos como Peña Negra I, donde se fechan entre el 900/800 y el 700 a.C. (González Prats, 1992: 249, 253). Más cercanamente, Quintana y Cruz (1996: 34), valorando los datos externos e internos más al día en el centro del valle del Duero, las sitúan grosso modo entre principios del siglo IX y fines delVIII a. C., es decir entre el 1100/ 1000 y el $850 / 750$ a.C.

Naturalmente es necesario llevar a cabo un estudio más profundo de este momento en el Sur de la Meseta Norte, con excavaciones que impliquen dataciones absolutas fiables y datos arqueológicos en cantidad suficiente para establecer comparaciones. Pero por el momento, con lo que ahora sabemos, no hay motivos ya para seguir considerando

T. P., 56, n. ${ }^{\circ} 2,1999$ 
una perduración de Cogotas I, arrinconada y excepcional en estas tierras montañosas, mientras en su entorno se apuntaban a las nuevas tendencias venidas, al parecer principalmente, de la mitad meridional. La prueba más evidente es que los nuevos yacimientos del Hierro I están a los pies de Los Castillejos de Sanchorreja. El caso de la estratigrafía de Sanchorreja precisa pues de una explicación diferente, posiblemente de tipo sedimentológico y con ello, de la matización de las teorías de González-Tablas con respecto a las cerámicas a peine que él consideraba emparentadas con determinados patrones de la etapa anterior-Cogotas I-. Esto es algo que, de momento, no se podrá negar morfológicamente, pero ya de ninguna manera recurriendo a la proximidad cronológica y cultural de la fase de Sanchorreja Superior con Sanchorreja Inferior, por más que no encontremos un hiatus arqueológico entre ambos.

Es necesario comentar también las circunstancias que rodean el hábitat del Hierro I en el Sur de la Meseta Norte, sobre todo por cuanto difiere respecto a lo que va a suceder en la fase siguiente, el Hierro II. Los hábitats del Bronce Final en la zona que tratamos tienen una doble tendencia: los hay en llano, en lugares poco escarpados al borde de valles $y$ en lo alto de cerros que muestran con claridad una finalidad defensiva que incluso parece exagerada. Quien haya subido, sobre todo, a Cancho Enamorado, en el Cerro del Berrueco o a los Castillejos de Sanchorreja lo entenderá mejor. Unos y otros están mostrando sin duda, primero, que Cogotas I es una cultura que se desarrolla durante al menos quinientos años y, en consecuencia, que en tanto tiempo pudieron existir etapas en las que las circunstancias aconsejaran uno u otro tipo de hábitats. Segundo que, dentro de la organización de dicha cultura, puede haber habido poblados coetáneos de diferente tipo en función de algunas circunstancias, que por falta de datos desconocemos. Y, finalmente, no debe ser despreciada la idea de que poblados en altura se dieran en los momentos finales de Cogotas I, más que en las fases inicial y plena. Eso parece contrastado suficientemente a partir de lo que se conoce y de cómo se enjuicia la cultura material de yacimientos como Carpio Bernardo, la Mesa de Carpio y el citado Cancho Enamorado en Salamanca y, en Ávila, los de Los Castillejos de Sanchorreja, Las Cogotas o el poco conocido de La Tejeda (Orbita). Curiosamente Cancho Enamorado, Los Castillejos, La Mesa del Carpio, Carpio Bernardo y Las Cogotas, poblados todos ubicados en cerros escarpados, parecen corresponder a un momento terminal de Cogotas I, interrumpiendo su habitación antes de que aparezca ni una sola cerámica que implique al Hierro I. ¿Significa esta circunstancia que hacia los últimos tiempos de Cogotas I se produce una situación de intranquilidad general propiciada por el movimiento de pueblos y/o por el cambio cultural que entra por los Pirineos y por el Mediterráneo? Reiterando lo dicho anteriormente, elegir como lugar de habitación Cancho Enamorado, en lo alto del Cerro del Berrueco, debe indicar una situación muy difícil en ese sentido, otra explicación no cabe. Si los yacimientos en altura corresponden a esa hipotética intranquilidad transicional, lo cierto es que lo que siguió tras el cambio, a juzgar por lo visto en los yacimientos abulenses, fue lo manifestado por esos poblados en llano, previsiblemente anteriores a los de la etapa final, al lado de arroyos, sin especial preocupación defensiva, tal vez expresando con ello una cierta provisionalidad.

A esa aparente despreocupación en la búsqueda de hábitats defensivos del Hierro I va a seguir, ya durante el Hierro II, otra mentalidad diferente que no merece muchas explicaciones si se conocen los poblados de La Mesa de Miranda, Ulaca, Las Cogotas, La Tejeda o Los Castillejos, por citar sólo los abulenses, dentro de un panorama enteramente similar en todo el Sur de la Meseta Norte. El surgimiento de los oppida de la II Edad del Hierro, al parecer como único testimonio del hábitat de esa época, está indicando un cambio sustancial no sólo en cuanto a los posibles peligros que provocan la elección de lugares altos y su refuerzo con murallas, sino también una organización de la sociedad que se agrupará en grandes poblados con todo lo que eso debe suponer.

\section{BIBLIOGRAFÍA}

Álvarez Sanchís, J.; Ruiz, G.; Lorrio, A.; Benito López, J.E. y Alonso, P. (1998): "Las Cogotas: Anatomía de un oppidum vettón”. Homenaje a Sonsoles Paradinas. Ávila: 73-94.

BalAdo, A. (1989): Excavaciones en Almenara de Adaja: El poblamiento prehistórico. Excma Diputación deValladolid. Valladolid.

Benet, N. (1990): "Un vaso pintado y tres dataciones de C14 procedentes del Cerro de San Pelayo (Martinamor, Salamanca)". Numantia, Arqueología en Castilla y León, III: 77-94.

Benet, N.; JimÉnez, M.C. y Rodríguez, M.B. (1991): “Arqueología en Ledesma, una primera aproximación: la 
excavación en la Plaza de San Martín”. En M. Santonja (coord.): Del Paleolítico a la Historia. Museo de Salamanca. Salamanca: 117-136.

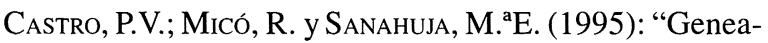
logía y cronología de la Cultura de Cogotas I (El estilo cerámico y el grupo de Cogotas I en su contexto arqueológico)". Boletín del Seminario de Arte yArqueología, LXI: 51-118.

Delibes de CAstro, G. (1995): "Del Neolítico al Bronce". En Historia de Ávila. I. Prehistoria e Historia Antigua. Institución Gran Duque de Alba. Ávila: 21-86.

Delibes, G. y Romero, F. (1992): "El último milenio a.C. en la cuenca del Duero. Reflexiones sobre la secuencia cultural". Complutum, 2-3: 233-258.

Delibes, G.; Romero, F. y Ramírez, M.'L. (1995): "El poblado céltico de El Soto de Medinilla (Valladolid). Sondeo estratigráfico de 1989-90”. En G. Delibes, F. Romero y A. Morales (ed.): Arqueología y Medio Ambiente. El Primer milenio a. C. en el Duero Medio. Junta de Castilla y León. Valladolid:149-177.

Delibes, G.; Romero, F.; SAnZ, C.; Escudero, Z. y SAN Miguel, L.C. (1995): "Panorama arqueológico de la Edad del Hierro en el Duero Medio”. En G. Delibes, F. Romero y A. Morales (ed.): Arqueología y MedioAmbiente. El Primer milenio a. C. en el Duero Medio. Junta de Castilla y León. Valladolid: 49-146.

FABIÁN, J.F. (1985). "El Cerro del Berrueco. Casi diez mil años de habitación ininterrumpida". Revista de Arqueología, 56: 6-17.

- (1986-1987): "El Bronce Final y la Edad del Hierro en el Cerro del Berrueco (Ávila-Salamanca)". Zephyrus, XXXIX-XL: 273-287.

García, M. y UrTeAGA, M. (1985): "La villa medieval y el poblado de la Edad del Hierro de la Mota (Medina del Campo, Valladolid)". Noticiario Arqueológico Hispánico, 23: 61-140.

GonZÁlez Prats, A. (1992): "Una vivienda metalúrgica en la Peña Negra (Crevillente-Alicante). Aportaciones al conocimiento del Bronce Atlántico en la Península Ibérica". Trabajos de Prehistoria, 49: 243-257.

GonZÁLEZ-TABLAS, F.J. (1986-1987): "Transición a la Segunda Edad del Hierro". Zephyrus, XXXIX-XL: 49-59.

- (1988-1989): "La cultura de El Soto de Medinilla.Algunas consideraciones”. Zephyrus, XLI-XLII: 331-338.

- (1989): "Los niveles superiores de Sanchorreja. La Primera Edad del Hierro en el borde meridional de la Meseta". Trabajos de Prehistoria, 46: 117-128.

- (1990): La necrópolis de Los Castillejos de Sanchorreja. Su contexto histórico. Acta Salmanticensia. Estudios Geográficos e Históricos, 69. Salamanca.

MALUquer DE Motes, J. (1958): Excavaciones arqueológicas en el Cerro del Berrueco (Salamanca). Acta Salmanticensia, XIV. Salamanca.

Martín Valls, R. (1986-1987): "La Segunda Edad del Hierro: Consideraciones sobre su periodización". Zephyrus, XXXIX-XL: 58-87.

MoRÁN, C. (1924-1925): Excavaciones arqueológicas en el Cerro del Berrueco. Memoria 65 de la Junta Superior de Excavaciones y Antigüedades. Madrid.

PiñEL, C. (1976): "Materiales del poblado de Las Paredejas en el Cerro del Berrueco. Una nueva arracada". Zephyrus, XXVI-XXVII: 351-368.

QuintANA, J. y CRUZ, P.J. (1996): "Del Bronce al Hierro en el centro de la Submeseta Norte. (Consideraciones desde el Inventario Arqueológico de Valladolid)". Boletín del Seminario de Arte y Arqueología, LXII: 9-78.

ROMERo CARNICERo, F. (1980): “Notas sobre la cerámica de la Primera Edad del Hierro en la cuenca media del Duero". Boletín del Seminario de Arte y Arqueología, XLVI: 137-153.

RuizZapatero, G. y Álvarez Sanchís, J. R. (1995): “Las Cogotas: Oppida and the roots of urbanism in the Spanish Meseta". En B.W. Cunliffe y S.J. Keay (ed.): Social Complexity and the development of towns in Iberia: from the CopperAge to the second century $A D$. Proceedings of the British Academy, 86. London: 209-235.

T. P., 56, n. ${ }^{\circ} 2,1999$ 